\title{
Redesign of a Grignard-Based Active Pharmaceutical Ingredient (API) Batch Synthesis to a Flow Process for the Preparation of Melitracen $\mathrm{HCl}$
}

Pedersen, Michael J.; Skovby, Tommy; Mealy, Michael J.; Dam-Johansen, Kim; Kiil, Søren

Published in:

Organic Process Research and Development

Link to article, DOI:

10.1021/acs.oprd.7b00368

Publication date:

2018

Document Version

Peer reviewed version

Link back to DTU Orbit

Citation (APA):

Pedersen, M. J., Skovby, T., Mealy, M. J., Dam-Johansen, K., \& Kiil, S. (2018). Redesign of a Grignard-Based Active Pharmaceutical Ingredient (API) Batch Synthesis to a Flow Process for the Preparation of Melitracen $\mathrm{HCl}$. Organic Process Research and Development, 22(2), 228-235. https://doi.org/10.1021/acs.oprd.7b00368

\section{General rights}

Copyright and moral rights for the publications made accessible in the public portal are retained by the authors and/or other copyright owners and it is a condition of accessing publications that users recognise and abide by the legal requirements associated with these rights.

- Users may download and print one copy of any publication from the public portal for the purpose of private study or research.

- You may not further distribute the material or use it for any profit-making activity or commercial gain

- You may freely distribute the URL identifying the publication in the public portal 


\section{Redesign of a Grignard-Based API Batch Synthesis}

2 to a Flow Process for the Preparation of Melitracen

$3 \mathrm{HCl}$

4 Michael J. Pedersen, ${ }^{\dagger, \ddagger}$ Tommy Skovby, ${ }^{\dagger}$ Michael J. Mealy, ${ }^{\dagger}$ Kim Dam-Johansen, $^{\ddagger}$ Søren Kiil ${ }^{*}, \neq$

$5 \quad{ }^{\dagger}$ H. Lundbeck A/S, Oddenvej 182, 4500 Nykøbing Sjælland, Denmark

$6 \ddagger$ Department of Chemical and Biochemical Engineering, Technical University of Denmark,

7 DTU, Building 229, 2800 Kgs. Lyngby, Denmark

8 
Synopsis

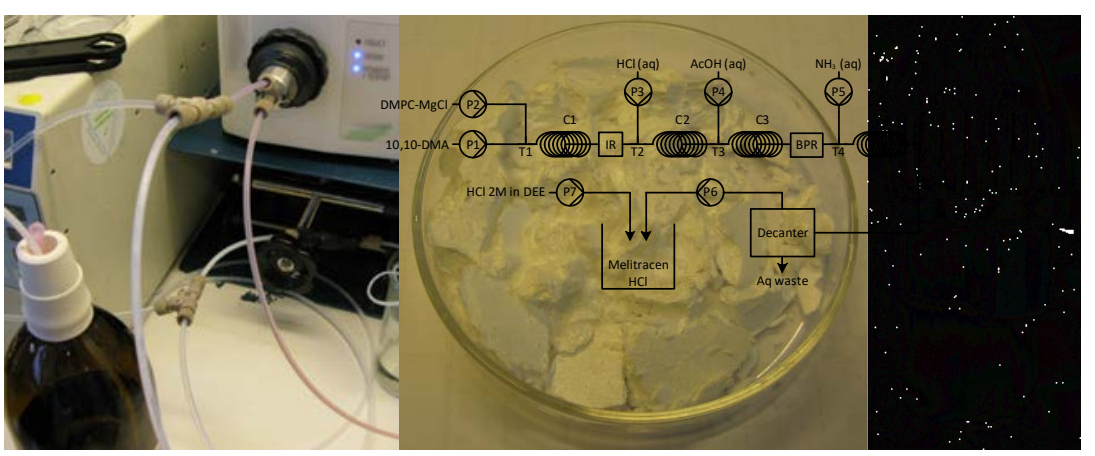

11 


\section{Abstract}

13 A Grignard-based batch process, for the preparation of Melitracen $\mathrm{HCl}$, has been redesigned to

14 fit a continuous reactor system. The Grignard addition is carried out at room temperature, with

15 subsequent hydrolysis of the magnesium alkoxide intermediate followed by dehydration of the

16 resulting alcohol. The product is further worked-up by simple gravimetric phase separation and

17 then crystallized with $2 \mathrm{M} \mathrm{HCl}$ in diethyl ether to afford pure Melitracen $\mathrm{HCl}$. All steps in the

18 laboratory setup were concatenated and the setup was proven capable of producing a significant

19 portion of the commercial quantities of Melitracen $\mathrm{HCl}$. The flow setup profits from a reduced

20 footprint, lower energy consumption, fewer synthetic steps and reduced raw material usage

21 compared to the batch process.

22 Keywords: Grignard alkylation, Flow chemistry, API synthesis, liquid phase separation. 


\section{Introduction}

25 The efficiency of the pharmaceutical industry has been a widely discussed topic throughout the

26 past decade. The debate has been broad, ranging from early target drug development to the actual

27 production and distribution of pharmaceuticals. ${ }^{1-6}$ Expiring patents and empty pipelines have

28 forced pharmaceutical companies to look for alternative methods to remain competitive against

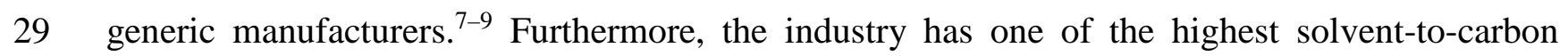

30 ratios, ${ }^{10}$ which in combination with the fact that most of these solvents have high environmental

31 impacts has given the industry a somewhat damaged reputation. ${ }^{5,10-13}$ In addition, the authorities

32 have steadily increased the tightening of legislative requirements for pharmaceutical

33 manufacturing, in both development and production. ${ }^{3,5}$

34 With respect to the production of active pharmaceutical ingredients (APIs), the focus has

35 especially been on batch methods and their insufficiency, especially their mass and heat transfer

36 properties. ${ }^{14,15}$ As early as the 1970 s, Popov ${ }^{16}$ suggested continuous manufacturing as a method

37 for improving the efficiency of pharmaceutical production. However, it was not until the last

38 decade that progress was seen. The establishment of the pharmaceutical round table and the

39 increased interest from academia and industry have been driving the transformation

40 forwards. ${ }^{4,5,17-20}$ The authorities have since 2002 acknowledged new production methods and

41 strategies within manufacturing. Process analytical technology (PAT) approaches and

42 Quality-by-Design (QbD) concepts have been important factors in the acceptance of continuous

43 manufacturing by the authorities. $9,21,22$

44 Earlier publications concerning the new paradigm of pharmaceutical manufacturing often

45 focused on single synthesis steps and unit operations, often with the use of microreactor 46 technology. ${ }^{23,24}$ Later trends have changed the focus towards multiple synthesis steps, 
47 pharmacy-on-demand and end-to-end manufacturing. ${ }^{17-19,25}$ As the trend has moved from single

48 step to end-to-end manufacturing, ${ }^{18}$ the previous out-scaling concept ${ }^{23}$ of microreactors has also

49 been replaced by mini-scale flow systems. ${ }^{18,20,26-28}$ The scale-up of a continuous setup needed to

50 meet full-scale requirements is often minor; hence the benefits such as mass and heat transfer are

51 almost comparable to microreactor technology. ${ }^{15}$

52 Reactions having multiple phases still pose a significant challenge within flow chemistry. ${ }^{29-31}$

53 Flow reactors are known for being poor at handling solid material due to clogging issues, with

54 some exceptions such as packed bed reactors with fixed catalytic material. Breakthroughs for

55 flow reactors that can handle solid reactants or products have within recent years been

56 demonstrated, such as the desulfurization of substituted thioimidazoles by Baxendal et al. ${ }^{32}$, the

57 powder dosing unit for a CSTR demonstrated by $\mathrm{Hu}$ et al. ${ }^{33}$ and precipitation in flow

58 demonstrated by Baxendal et al. ${ }^{34}$

59 The pharmaceutical industry is notorious for their usage of solid compounds, either as 60 reactants, intermediates or APIs. ${ }^{29,31}$ Low solubility is often a huge obstacle for applying the

61 chemistry to a flow setup, unless alternative methods are applied. ${ }^{2,31}$ Solubility is one of the key

62 parameters when designing a reactor setup and an instructive discussion may be found in

63 Pedersen et al. ${ }^{20}$ In cases of high solubility, the simple use of a plug flow reactor (PFR) can be

64 applied, often with great success and larger throughput. ${ }^{28,35}$ The challenging part then becomes

65 the purification of the product from impurities and unreacted reactants, as well as the final

66 isolation of the product. Many old batch processes utilize the benefits of precipitation as a

67 purification step, hence altering an old batch process to fit a flow setup requires new ways to

68 overcome these challenges. ${ }^{2,20,29}$ 
69 Grignard reactions serve as a commonly used method for the formation of carbon-carbon

70 bonds in the development of APIs ${ }^{36,37}$. The exothermic behavior of the Grignard reaction makes

71 it ideal for continuous production. Several demonstrations of Grignard reactions in flow have

72 been done within the last decade: Kopach et al..$^{38,39}$ demonstrated the use of a CSTR technology;

73 Pedersen et. $a l^{20,26,40}$ demonstrated the use of a heterogeneous slurry filter reactor; Mateos et al. ${ }^{41}$

74 studied the formation of ketone by nucleophilic Grignard addition to nitril groups by use of flow

75 methods; Lonza ${ }^{42-44}$ has demonstrated the use of micro reactor technology.

76 Chemistry

77 As illustrated in Scheme 1, four synthetic steps are involved in the manufacturing of

78 Melitracen $\mathrm{HCl}(\mathbf{6})$. The four steps are a classic Grignard addition to a ketone, a hydrolysis of a

79 magnesium alkoxide, a dehydration of an alcohol and a salt precipitation to isolate the API. The

80 Grignard addition is between 10,10-dimethylanthrone (10,10-DMA (1)) and

813 -(N,N-dimethylamino)propylmagnesium chloride (DMPC-MgCl (2)), resulting in formation of

82 the magnesium alkoxide $\mathbf{3}$. The magnesium alkoxide $\mathbf{3}$ is then hydrolyzed to the alcohol $\mathbf{4}$ and

83 dehydrated to form product 5. The last step is a crystallization of the API as a salt, where $\mathrm{HCl}$ is

84 added to obtain the Melitracen $\mathrm{HCl}(\mathbf{6})$.

85 Scheme 1: Syntheses of magnesium alkoxide 3, alcohol 4 and dehydrated product 5 in the manufacturing process of Melitracen $\mathrm{HCl}$ 6, from ketone $\mathbf{1}$ and Grignard reagent $\mathbf{2}$. 
<smiles>COC1(CCCC(C)C)c2ccccc2C(C)(C)c2ccccc2C1(C)CCCN(C)C</smiles><smiles>CN(C)CC/C=C1\c2ccccc2C(C)(C)c2ccccc2C1(C)C(C)(C)C(C)(C)C(C)(C)C</smiles>

\section{Current Batch Synthesis}

89 The current batch synthesis involves individual synthetic steps, as illustrated in Figure 1.

90 DMPC-MgCl 2 is made in-house before it is used, due to its limited storage shelf life, in a 91 toluene-THF solvent mixture. THF is present in trace amounts in order to stabilize the

92 magnesium in the Grignard reagents. ${ }^{45}$ A solution of 10,10-DMA 1 is prepared in toluene and is

93 slowly transferred to the DMPC-MgCl 2, maintaining a temperature of $50^{\circ} \mathrm{C}$. DMPC-MgCl 2 is

94 used in an equivalence of 1.6 compared to 10,10-DMA 1. The formed magnesium alkoxide 3 is

95 hydrolyzed with water and acetic acid (80\%). The aqueous phase is discarded and concentrated

96 hydrochloric acid (37\%) is used to dehydrate alcohol 4 to form dehydrated product $\mathbf{5}$. Toluene is

97 replaced with ethanol by a solvent swap. Crystallization of the dehydrated product 5 from the

98 ethanol phase is done with $\mathrm{HCl}$ gas to obtain the final Melitracen $\mathrm{HCl}$ (6), which is subsequently

99 isolated by filtration. 


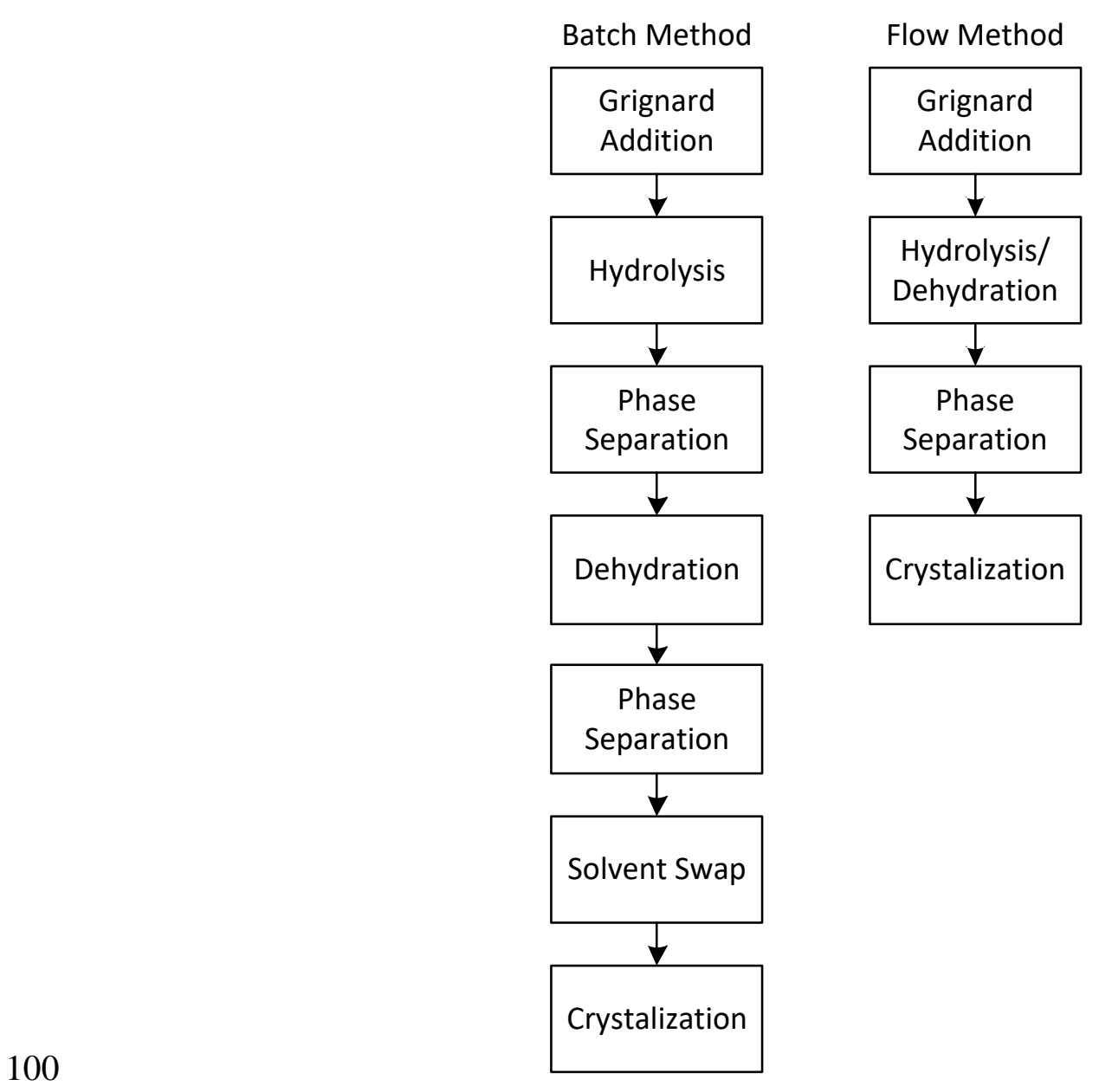

$101 \quad$ Figure 1: The operational steps involved in the current batch method and the simplification achieved by the flow setup.

103 Investigational Strategy

104 The API manufacturing strategy at H. Lundbeck A/S is focused on continuous production. 105 Melitracen HCl synthesis currently occupies significant production facilities and is produced by 106 routine batch synthesis procedures. The process shows potential for being redesigned to fit a 107 continuous reactor setup, with potential for significant simplification of the operation and the 108 synthetic route. This article describes the laboratory work for redesigning the process to fit a 109 continuous reactor setup for the Grignard addition to the final Melitracen HCl crystallization. 


\section{Experimental Section}

\section{Screening Experiments}

112 The routine batch synthesis for production of Melitracen HCl 6 was considered suitable for

113 redesign into a flow process, as most of the synthetic steps are categorized as fast reactions. ${ }^{31}$

114 The current batch methods could possibly be transferred directly into a flow setup, providing the

115 common benefits achieved when changing from batch to continuous processing. However,

116 additional savings could potentially be achieved with the flow setup if simplifications of aspects

117 such as the solvent choice and synthetic steps were possible. Classic batch screening experiments

118 were conducted to assist in the decision on and design of a flow setup and, based on these

119 experiments, the flow setup decided on was to be experimentally verified afterwards.

\section{Solubility of Reactants and Products in Solvents}

121 The first consideration in the process for redesigning Melitracen HCl 6 synthesis is the 122 solubility of reactants, intermediates and products. Solubility is one of the key parameters when 123 designing a reactor setup. The primary focus was on the Grignard addition step, where reactants 124 10,10-DMA 1, DMPC-MgCl 2 and magnesium alkoxide product 3 are of interest. DMPC-MgCl 1252 already has a high solubility and was not tested further. 10,10-DMA 1 is a solid starting 126 material and needs to be dissolved before it can react with DMPC-MgCl 2. The solubility of 127 10,10-DMA 1 should therefore be tested in potential solvents and at different temperatures. 128 Magnesium alkoxide 3 is not easily isolated, as the magnesium halide part easily reacts with 129 water and moisture. Instead of determining the exact solubility of magnesium alkoxide $\mathbf{3}$, a 130 qualitative first estimate of its capability to stay in solution could be sufficient. The requirement 131 is, of course, that the concentration of magnesium alkoxide $\mathbf{3}$ in the reaction mixture is 
132 representative of the concentrations of the 10,10-DMA 1 and DMPC-MgCl 2 intended for the

133 synthesis. The later synthetic steps should be tested accordingly for solubility where necessary,

134 since low solubility in these steps could require a lower concentration of 10,10-DMA 1 and

135 DMP-MgCl 2 to have a fully operational flow setup from start to end of the synthesis.

136 The solubility experiments on 10,10-DMA 1 focused on three solvents to be verified: toluene, 137 tetrahydrofuran (THF) and 2-methyltetrahydrofuran (MeTHF), all of which are suitable 138 candidates for later full-scale production. The solubility temperature was tested up to $20^{\circ} \mathrm{C}$, 139 which is to be considered the high limit due to ambient temperatures if no heat tracing should be 140 applied to pumps and pipes. Figure 2 shows the solubility of 10,10-DMA 1 in the three solvents, 141 where THF shows a significantly higher solubility than toluene or MeTHF.

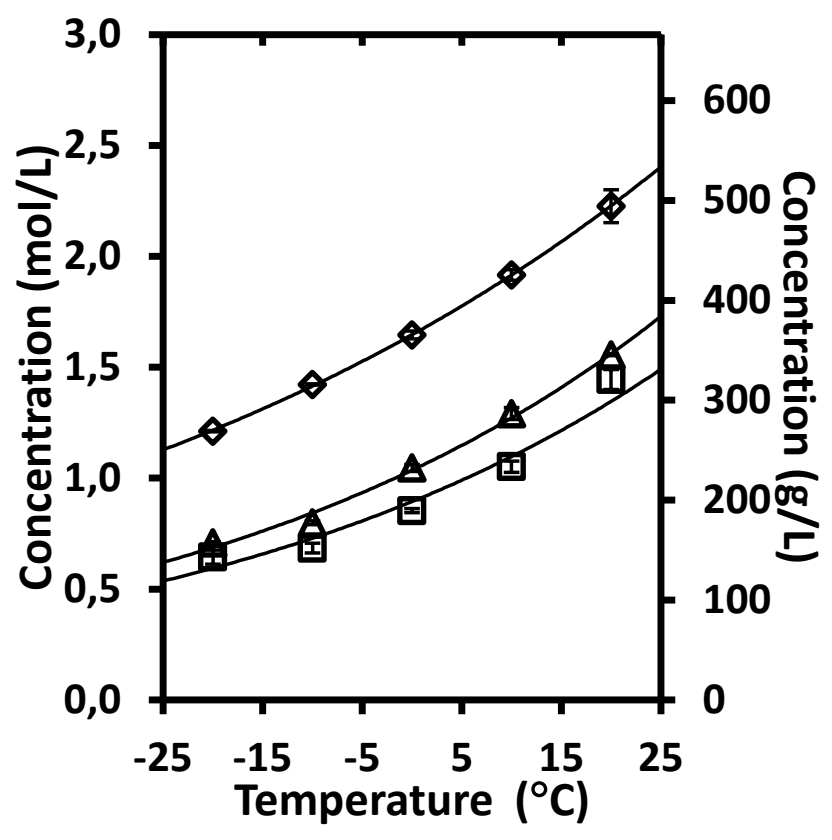

$143 \quad$ Figure 2: The solubility of 10,10-DMA 1 in toluene $(\square)$, THF $(\diamond)$ and MeTHF $(\triangle)$. The 144 10,10-DMA 1 has high solubility even at low temperatures in the tested solvents. The solubility 145 in THF is significantly higher compared to MeTHF and Toluene (approximately 100 g/L more 10,10-DMA 1). 
148 toluene were to be used as in the batch process, trace amounts of ether would still be needed to 149 stabilize the magnesium in DMPC-MgCl 2.

150 The concentration of 10,10-DMA 1 in THF was set to the lower side of $20^{\circ} \mathrm{C}(1.8 \mathrm{~mol} / \mathrm{L}, 400$ $151 \mathrm{~g} / \mathrm{L}$ ) to minimize the risk of precipitation while operating a flow setup. The DMPC-MgCl 2 was 152 available at approximately 1.5 M concentration in THF from the production and it was decided 153 to proceed with this concentration. A couple of quick qualitative batch experiments were carried 154 out to verify whether the magnesium alkoxide 3 could remain soluble in the reaction mixture, as 155 it was not possible to isolate the unstable magnesium alkoxide $\mathbf{3}$ for a solubility study. These 156 experiments came out positive for the desired concentrations of 10,10-DMA 1 and DMPC-MgCl

1572 and no further testing of the solubility of magnesium alkoxide $\mathbf{3}$ was found necessary.

158 Phase Separation: Organic Phase and Aqueous Waste

160 A batch experiment, representing the expected concentration for the flow setup, was used to 161 verify the potential for phase separation of THF from the aqueous phase. The DMPC-MgCl 2 162 was slowly added in excess amounts with a dripping funnel to a round-bottom flask of the 163 10,10-DMA 1 solution. The mixture was afterwards hydrolyzed with water and acetic acid 164 (80\%). The addition of the acid caused the $\mathrm{pH}$ of the mixture to become slightly acidic ( $\mathrm{pH} \sim 6)$ 165 and an one-phase mixture was achieved. The $\mathrm{pH}$ was adjusted with aqueous ammonia (25\%) and 166 at pH 8 a two-phase mixture appeared. Alcohol 4 was distributed with 63\% in the organic phase 167 and 37\% in the aqueous, according to HPLC assay. Adjusting the $\mathrm{pH}$ in the aqueous phase to 10 168 with additional aqueous ammonia (25\%) resulted in an additional organic phase, with less than $1691 \%$ alcohol 4 left in the aqueous phase. 
170 Alcohol 4 in the organic phase was then dehydrated with hydrochloric acid (37\%), followed by 171 adjustment of the $\mathrm{pH}$ to 10 with aqueous ammonia (25\%). Adjusting the $\mathrm{pH}$ to 10 allowed a

172 phase separation with more than $99 \%$ of the product in the organic phase and with a 99\% purity

173 of the dehydrated product 5. During the hydrolysis and dehydration, a minor precipitation of

174 solid material was formed that easily dissolved as the reaction progressed and should therefore 175 not be a major concern for a flow setup.

176 At $\mathrm{pH} \geq 10$ the tertiary amine is completely deprotonated, causing the products $\mathbf{4}$ and $\mathbf{5}$ to

177 become almost insoluble in water, thereby achieving excellent separation. At $\mathrm{pH} \leq 10$ the tertiary 178 amine becomes protonated and is soluble both in the aqueous and organic phase. If a clean phase 179 separation had not been possible, changing the synthesis solvent to MeTHF could have 180 simplified the workup of the products $\mathbf{4}$ or $\mathbf{5}$ from the aqueous phase, as MeTHF is not miscible 181 with water.

\section{One-Step Hydrolysis and Dehydration}

183 The ability to phase separate both the alcohol $\mathbf{4}$ and the dehydrated product $\mathbf{5}$ in THF enabled a 184 simplification of the targeted flow method. Ideally, hydrolysis and dehydration should be 185 possible in one step, hence saving a phase separation and combining two synthetic steps into one.

186 Screening for a potential acid for the one-step hydrolysis and dehydration was done, focusing on 187 acetic acid and hydrochloric acid, either separately or in combination. Table 1 shows the results 188 of the product formation based on the different acid systems.

189 Table 1: Screening of different acids for direct hydrolysis and dehydration of the magnesium 190 alkoxide 3 to the dehydrated product 5 .

\begin{tabular}{|c|c|c|}
\hline Acid Solution & Product (\%) & Phase Separation (\%) \\
\hline HCl 37\% (aq.) & Dehydrated 5 (100\%) & $>99$ \\
\hline
\end{tabular}




\begin{tabular}{|c|c|c|}
\hline AcOH 80\% (aq.) & Alcohol 4 (100\%) & $>99$ \\
\hline HCl 37\% (aq.)/AcOH 80\% (aq.) (1:1) & $\begin{array}{c}\text { Dehydrated 5 (90\%) } \\
\text { Alcohol 4 (10\%) }\end{array}$ & $>99$ \\
\hline
\end{tabular}

191

192 As seen in Table 1, only hydrochloric acid was able to hydrolyze and dehydrate the 193 magnesium alkoxide mixture in one step. The experiment with hydrochloric acid resulted in 194 significant heat development and an immediate precipitation of solids that potentially could be 195 critical, even though it dissolved within a few minutes. An additional set of screening 196 experiments was done to verify the potential of a lower concentration of hydrochloric acid. 197 These experiments were carried out to verify whether the immediate precipitation of solid could 198 be avoided and whether the energy released from the hydrolysis and dehydration could be

199 distributed, as both steps are exothermic. Equal volumes of hydrochloric acid with different 200 concentrations (1, 3, 6, 9 and $12 \mathrm{M})$ were used. For the concentrations lower than $6 \mathrm{M}$, it was not 201 possible to achieve full dehydration at ambient temperature. For the concentrations equal to $6 \mathrm{M}$ 202 and higher, full dehydration was obtained, but all concentrations resulted in precipitation of a 203 white solid that dissolved after few minutes of standing. From a production and environmental 204 perspective, the more concentrated hydrochloric acid is the optimal choice; less aqueous waste is 205 generated if the acid used is stoichiometric. Given the fact that precipitation could not be avoided 206 and the production perspective, it was decided to proceed with $12 \mathrm{M}$ hydrochloric acid.

207 Precipitation of Melitracen HCI from THF

208 The dehydrated product 5 was crystallized as the final $\mathrm{HCl}$ salt in the $\mathrm{THF}$ in a batch 209 experiment, in order to remove a solvent swap to ethanol. The crystallization was carried out 210 with $2 \mathrm{M} \mathrm{HCl}$ in $\mathrm{Et}_{2} \mathrm{O}$, as this was considered more suited for a later flow process and more 211 easily implemented in the laboratory setup. An equivalence of $1.1 \mathrm{HCl}$ was used and the 
212 requirement was an achievement of $\mathrm{pH}<2$. The mixture was kept stirred during the

213 crystallization and carried out at ambient temperature. After 10 minutes, fine white solids started

214 to form, followed by a massive precipitation of Melitracen $\mathrm{HCl}$ 6. The Melitracen $\mathrm{HCl} 6$ was

215 filtered with a Büchner funnel and washed with THF. The isolated yield was 80\% and within the

216 specifications for the in-house analysis methods used in the routine production (CHN, TGA,

217 UV-vis, HPLC, melting point). Figure 3 is a microscope picture of the isolated Melitracen $\mathrm{HCl} 6$.

218 For full-scale production, the $\mathrm{HCl}$ gas would still be more desirable for the crystallization and the

$2192 \mathrm{M} \mathrm{HCl}$ in $\mathrm{Et}_{2} \mathrm{O}$ merely serves as a proof of concept for the laboratory flow setup.

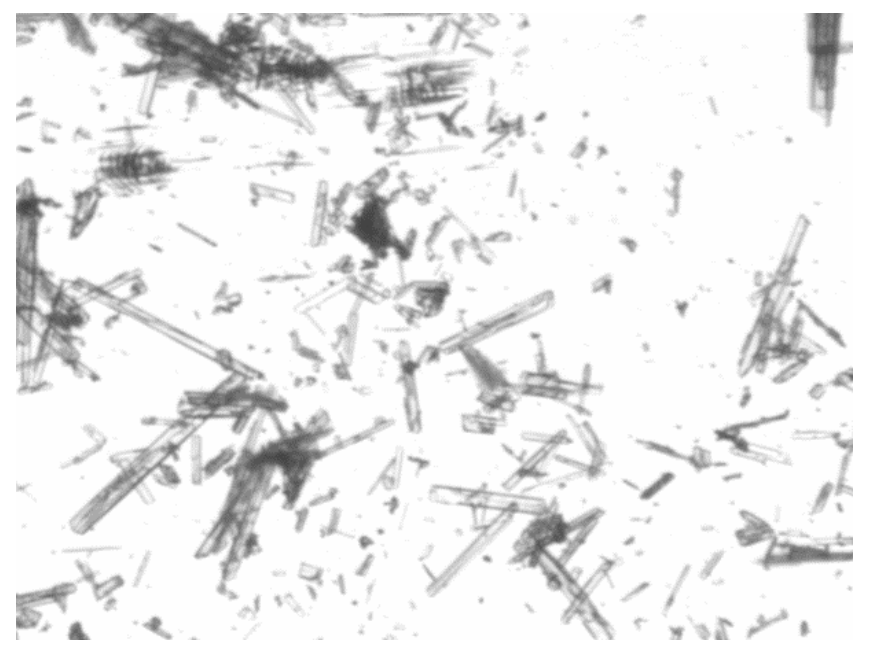

Figure 3: Microscope picture of the isolated Melitracen $\mathrm{HCl} 6$ from the THF solution.

\section{Flow Process}

223 The initial batch screening experiments all indicated that the chemistry should be run in PFRs.

224 This decision is based on several parameters from the screening experiments. In particular, the 225 high solubility of the reactants and products makes the synthesis ideal for PFRs. Additionally, all 226 of the synthesis steps are categorized as fast (full conversion within minutes) and hence small 227 reactor volumes can be used. The final setup is illustrated in Figure 4 as a flow sheet. All tubing 228 was 1/8” OD and 1/16” ID and made from PTFE; the T-mixer was of PEEK material ID 0.04”. 
229 All synthetic steps were performed at ambient temperature, with no active cooling or heating. If

230 the reactor system was to be scaled significantly, consideration of active cooling and heating

231 should be taken into account due to potential safety and control related issues. Every step, except

232 for the addition of acetic acid and the decanter phase separation, is exothermic. The decanter was

233 a $100 \mathrm{~mL}$ glass bottle, fitted for the purpose with an in-house-made PTFE lid. After the Grignard

234 addition (T1,C1) of DMPC-MgCl 2 to 10,10-DMA 1, a flow IR $10 \mu \mathrm{L}$ head from Mettler Toledo

235 was applied for in-line monitoring of the conversion and reaction. After the acetic acid addition

236 (T3,C3), a 100 psi back pressure regulator (BPR) was applied to avoid boiling of the THF due to

237 the hydrolysis and dehydration taking place at the $\mathrm{HCl}$ addition (T2,C2). The choice of placing

238 the BPR is due to precipitation of solid material right after the $\mathrm{HCl}$ addition that is fully

239 dissolved throughout the acetic acid coil. The HCl precipitation was done by collection of the

240 two streams in a flask. A number of different pumps were used, all of them being positive

241 displacement pumps for dosing purposes. Knauer Azura P 2.1S HPLC pumps with $10 \mathrm{~mL}$

242 stainless steel pump heads (P1 and P2) were used for the 10,10-DMA (1) and DMPC-MgCl (2);

243 a Syrris Asia pump (dual pump) equipped with 0.5 and $1.0 \mathrm{~mL}$ glass syringes was used for both

244 hydrochloric acid (P3) and acetic acid (P4). A Merck-Hitachi HPLC pump with a $10 \mathrm{~mL}$

245 stainless steel pumphead was used for the aqueous ammonia (P5) and Ismatec Reglo RH00

246 piston pumps were used for the decanter outlet (P6) and the $2 \mathrm{M} \mathrm{HCl}$ in $\mathrm{Et}_{2} \mathrm{O}$ (P7). The two

247 Knauer pumps were specially ordered with PTFE gasket intended for Grignard reagents and THF

248 solvent. The remaining pumps were chosen based on availability in the laboratory. The flow rate

249 was determined in accordance with the maximum capacity of each pump and the limitation was

250 the pump used for the acetic acid. 


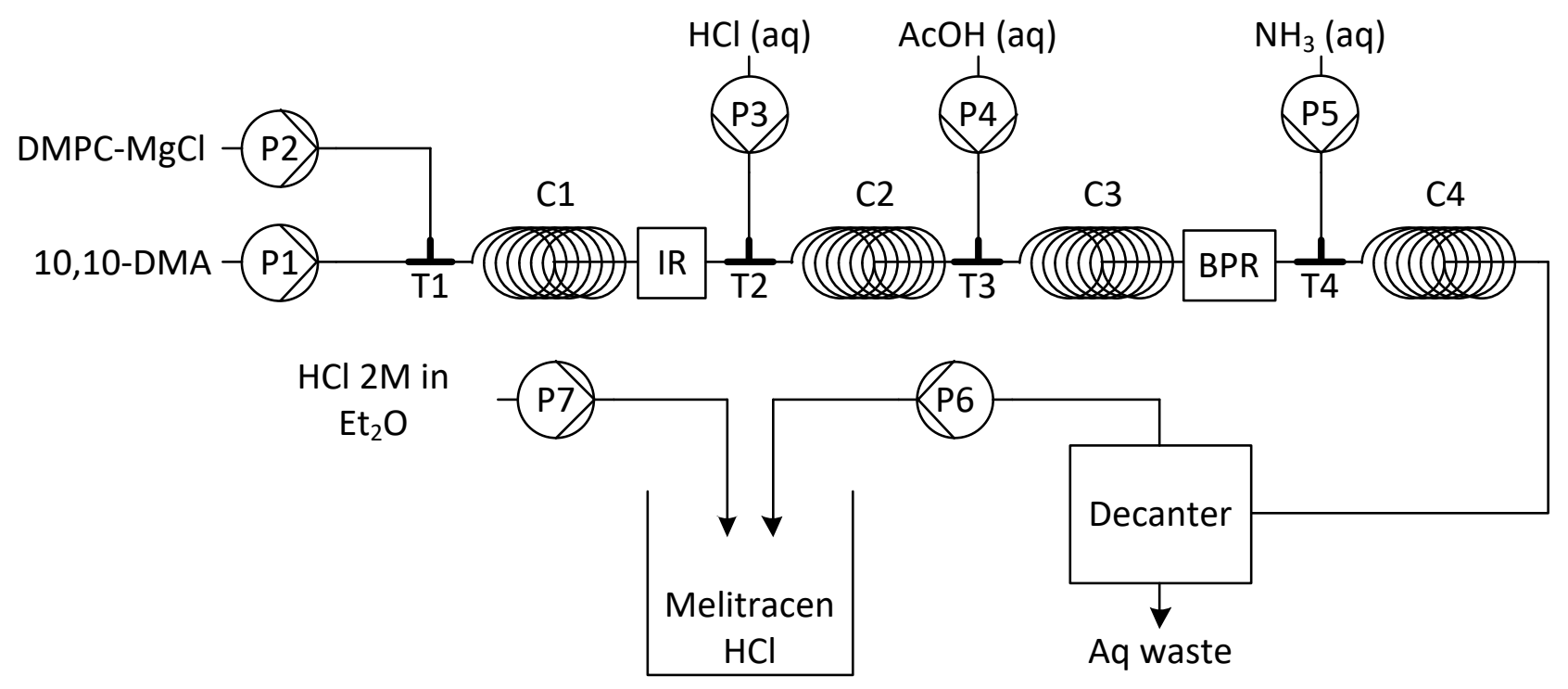

253 Figure 4: Flow sheet of the flow reactor setup for the redesign of the Melitracen HCl synthesis.

254 Pump (P), Coil (C), T-mixer (T), Infrared In-line flow cell (IR), Back pressure regulator (BPR).

\section{Results and Discussion}

\section{Stepwise Verification of Flow Reactor Parts}

257 A stepwise implementation and verification of each step was done to minimize the risk of 258 operational problems, while operating the entire setup as illustrated in Figure 4. The major risks 259 were considered to be clogging issues and separation performance.

260 The Grignard addition of DMPC-MgCl 2 to 10,10-DMA 1 was the first part to be verified and 261 an equivalence of 1.1 DMPC-MgCl 2 was used to ensure full conversion of 10,10-DMA 1. Only 262 a few minutes of residence time were needed for the reaction to achieve full conversion of the 263 10,10-DMA 1. The reaction was easily followed visually, as the magnesium alkoxide 3 becomes 264 dark red/orange. The product stream was collected in a flask, where it turned to a more orange265 like appearance over time. 
267 solvent, but full conversion was achieved within minutes. Implementing the acetic acid stream

268 resulted in some alteration of the setup to account for the boiling of the THF, as full conversion

269 was not achieved. A back pressure regulator (BPR) of 100 psi was added to prevent the boiling

270 of the THF $\left(65^{\circ} \mathrm{C}\right.$ at STP). The BPR provided a stable flow that ensured a steady residence time

271 in the $\mathrm{HCl}$ coil (C2), resulting in the desired full conversion of the magnesium alkoxide $\mathbf{3}$ to the

272 dehydrated product 5. Adding the aqueous ammonia stream to the setup caused precipitation of

273 ammonium chloride salt. The precipitate was easily dissolved by addition of water. Due to lack

274 of pumps, it was decided to dilute the acetic acid to $40 \%$ from the original $80 \%$ and to double the

275 flow rate. From a production perspective, an additional pump with water would be better suited

276 as $80 \%$ acetic acid is the standard concentration in production. Acetic acid serves to assure that

277 the magnesium salt complex remains soluble after $\mathrm{pH}$ adjustment to basic conditions. The BPR

278 was originally implemented right after the $\mathrm{HCl}$ coil, but the white solid precipitate later caused

279 clogging of the BPR, so it was moved to be after the acetic acid stream where a full liquid

280 homogeneous phase was present. The choice of not moving it to be after the aqueous ammonia

281 coil was due to a small risk of having precipitation upon the addition thereof, as this was

282 observed in a previous run. At the end of the acetic acid addition during all adjustments, a full

283 one-phase homogeneous stream was constantly present and it was considered more stable to add

284 the BPR at this point in case of any fluctuation.

285 Having the entire setup running, the decanter was tested for the setup. A previous flow setup

286 had proved the decanter's capability for separating organic and aqueous phases from each other,

287 so that a single experiment was enough to demonstrate the decanter for this separation. The last

288 stream to be implemented was the $2 \mathrm{M} \mathrm{HCl}\left(\mathrm{Et}_{2} \mathrm{O}\right)$ stream for crystallization. At first, mixing of 
289 the two streams was attempted in a T-mixer (2.5 mm ID), but the low pressure pumps used 290 (Ismatec pumps) could not deliver a high enough pressure to avoid clogging. The clogging was 291 caused by evaporation of the solvents due to the low boiling points of both THF and $\mathrm{Et}_{2} \mathrm{O}$ and 292 the crystallization of Melitracen $\mathrm{HCl}(\mathbf{6})$ happening in the T-mixer. As an alternative, the two 293 streams (P6 and P7) were pumped individually into the collecting bottle. No optimization was 294 done to control the crystallization, as this was not the scope of the project, and for a full-scale 295 setup $\mathrm{HCl}$ gas would be a preferred choice. Figure 5 shows the fractions collected from the setup.

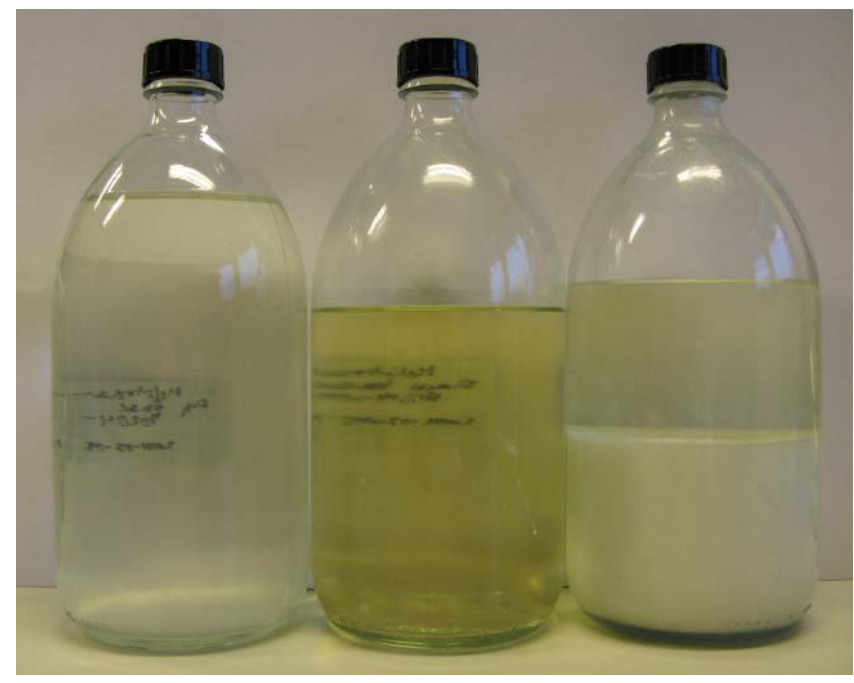

297 Figure 5: The collected fractions of product streams from the setup during continuous operation. 298 To the left is the aqueous waste from the decanter, at the center is the organic phase containing 299 dehydrated product 5 and to the right is the crystalline Melitracen $\mathrm{HCl} 6 \mathrm{API}$ and the mother liquid.

\section{Operation of Full Flow Setup}

302 The final flow setup, as illustrated in Figure 4, was operated for 300 minutes under steady state 303 conditions. The experiment was terminated at the point of complete utilization of the $2 \mathrm{M} \mathrm{HCl}$ 304 (Et $\left.{ }_{2} \mathrm{O}\right)$. For the first 30 minutes the setup was not in steady state due to a tube burst and fittings 
around the IR flow cell, but a steady state was achieved shortly after replacement of the broken

306 fittings. The tube burst was a result of a clog formed from Grignard reagent reacting with

307 residual water in the IR flow cell from previous cleaning. The flow rate of the system is given in

308 Table 2 and Table 3 provides the residence times in the important parts of the reactor.

309 Table 2: The reactor configurations and residence times, along with important observations, for the Melitracen $\mathrm{HCl} 6$ synthesis as operated with the flow setup (Figure 4).

\begin{tabular}{|c|c|c|c|c|}
\hline Reactor part & $\begin{array}{c}\text { Flow Rate } \\
(\mathrm{mL} / \mathrm{min})\end{array}$ & $\begin{array}{c}\text { Reactor } \\
\text { Volume }(\mathrm{mL})\end{array}$ & $\begin{array}{c}\text { Residence } \\
\text { Time }(\mathrm{s})\end{array}$ & Observation \\
\hline Coil 1 & 4.5 & 4.95 & 66 & $\begin{array}{c}\text { Deep red color from reaction. } \\
\text { Temperature higher than ambient, } \\
\text { lower than the boiling point of THF. }\end{array}$ \\
\hline Coil 2 & 5.5 & 1.98 & 21.6 & $\begin{array}{c}\text { Temperature is above the boiling } \\
\text { point of THF, 100 psi suppress } \\
\text { boiling. }\end{array}$ \\
\hline Coil 3 & 8.0 & 0.99 & 7.4 & $\begin{array}{c}\text { Stream becomes transparent with a } \\
\text { white solid that disappears into an } \\
\text { one-phase system. } \\
\text { pH }<2\end{array}$ \\
\hline Coil 4 & 9.9 & 1.98 & 6.0 & $\begin{array}{c}\text { One-phase system } \\
\text { pH }<2\end{array}$ \\
\hline $\begin{array}{c}\text { Decanter } \\
\text { (Org/Aq) }\end{array}$ & $9.9(4.5 / 5.4)$ & 100 & 606.1 & $\begin{array}{c}\text { Two-phase system } \\
\text { pH }>10\end{array}$ \\
\hline
\end{tabular}

311

312 Table 3: The flow rates and concentrations of the different reactants used in the flow setup.

\begin{tabular}{|c|c|c|c|}
\hline Reactants & Flow rate (mL/min) & Concentration (M) & Equivalence to 10,10-DMA 1 \\
\hline 10,10-DMA 1 & 2.0 & 1.8 & 1.0 \\
\hline DMPC-MgCl 2 & 2.5 & 1.5 & 1.05 \\
\hline $\mathrm{HCl}(\mathrm{aq})$ & 1.0 & $12(37 \%)$ & 3.33 \\
\hline $\mathrm{AcOH}(\mathrm{aq})$ & 2.50 & $7(40 \%)$ & 4.86 \\
\hline $\mathrm{NH}_{3}(\mathrm{aq})$ & 1.9 & $13.4(25 \%)$ & 7.07 \\
\hline
\end{tabular}




\begin{tabular}{|c|c|c|c|}
\hline $\mathrm{HCl}\left(\mathrm{Et}_{2} \mathrm{O}\right)$ & 2.25 & 2 & 1.25 \\
\hline
\end{tabular}

314 An IR flow cell was placed after coil 1 and was used to follow and ensure that full conversion

315 of 10,10-DMA 1 was achieved. Figure 6 shows the carbonyl peak of the 10,10-DMA $\mathbf{1}$ as it

316 progressed throughout the experiment. The trend line absorbance intensity of the peak is based

317 on area to zero baseline for the IR region of $1610-1580 \mathrm{~cm}^{-1}$ and is given in arbitrary units. The

318 off-line HPLC data in Table 4 confirms full conversion of 10,10-DMA 1. The replacement of the

319 tubing caused an exposure of the magnesium alkoxide 3 to the surrounding atmosphere (i.e.

320 moisture in the air), resulting in the deposit of magnesium salts on the IR diamond window.

321 Despite an attempt to clean the window, some deposit was still present, causing the small offset

322 from the zero baseline, which explains why zero is not achieved.

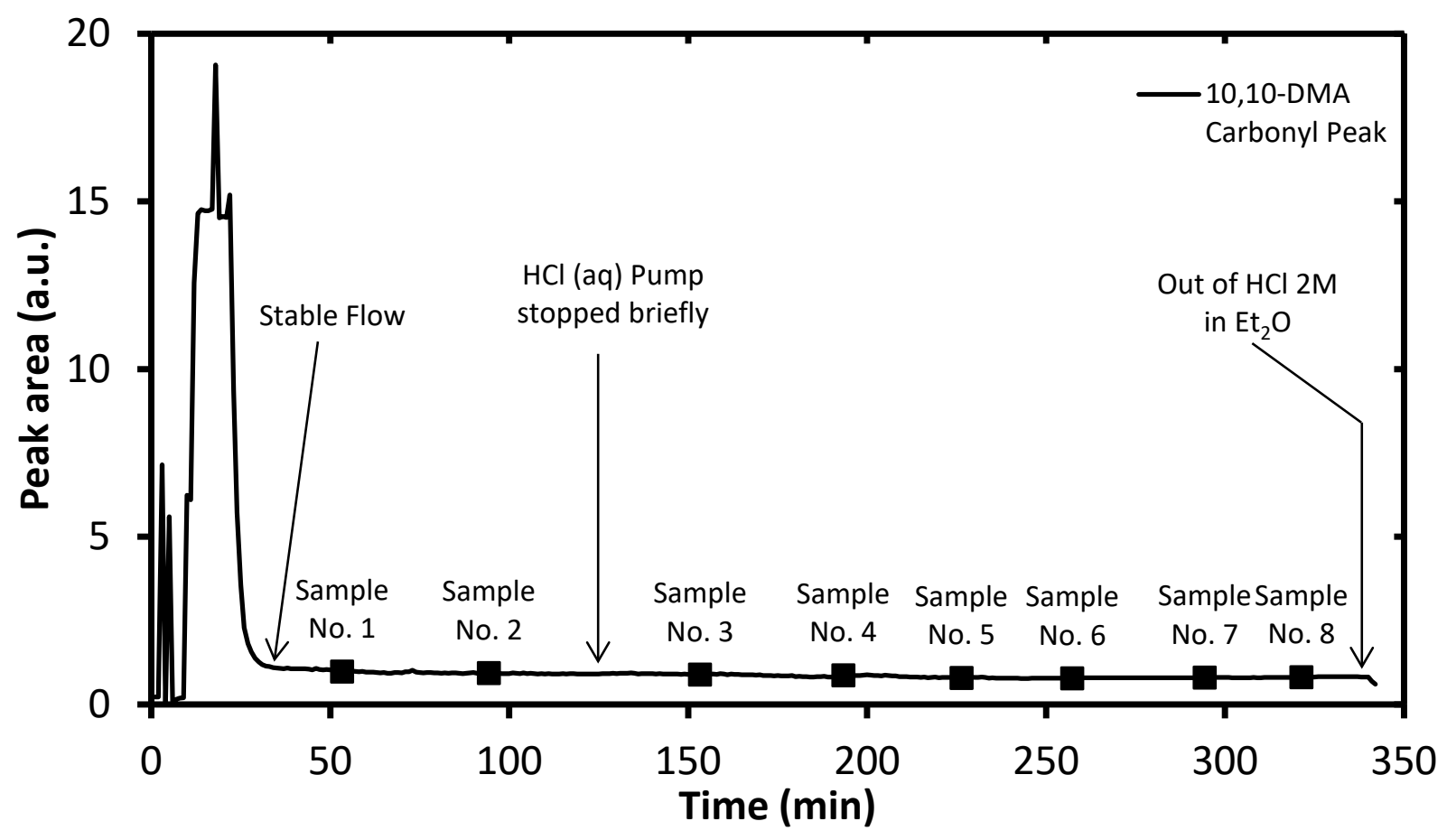

324 Figure 6: The IR data on the flow setup run, following the peak of the carbonyl functional group 325 of 10,10-DMA (1) and the reference samples for off-line HPLC analysis given in Table 4. Steady 

with THF and dried in a vacuum oven at $50{ }^{\circ} \mathrm{C}$ for 24 hours. The product was subjected to complete release analysis for the API and all product attributes were found to be within

331 specification. A total of $300 \mathrm{~g}$ of dry Melitracen $\mathrm{HCl}$ (6) was isolated from the flow setup, 332 requiring a consumption of approximately 240 g 10,10-DMA (1) starting material.

333 Table 4: The HPLC samples, where samples were collected from the aqueous waste stream of 334 the decanter, the crystallized Melitracen $\mathrm{HCl}(\mathbf{6})$ and the mother liquid, and a few from the organic phase of the decanter.

\begin{tabular}{|c|c|c|c|c|c|}
\hline $\begin{array}{c}\text { Sample } \\
\text { No. }\end{array}$ & Compound & $\begin{array}{c}\text { Crystallized } \\
\text { Product } \\
\text { (Area\%) }\end{array}$ & $\begin{array}{c}\text { Mother } \\
\text { Liquid } \\
\text { Area\%) }\end{array}$ & $\begin{array}{c}\text { Decanter } \\
\text { Aqueous } \\
\text { (Area\%) }\end{array}$ & $\begin{array}{c}\text { Decanter } \\
\text { Organic } \\
\text { (Area\%) }\end{array}$ \\
\hline 1 & Melitracen (5 or 6) & 100 & 97.65 & 62.0 & No sample \\
& Alcohol (4) & nd & nd & 38.0 & \\
& 10,10-DMA (1) & nd & 2.1 & nd & \\
& Other Impurities & nd & 0.2 & nd & \\
\hline 2 & Melitracen (5 or 6) & 100 & 97.8 & 37.8 & No sample \\
& Alcohol (4) & nd & nd & 62.1 & \\
& 10,10-DMA (1) & nd & 2.0 & nd & \\
& Other Impurities & nd & 0.2 & nd & No sample \\
\hline 3 & Melitracen (5 or 6) & 100 & 96.3 & 20.5 & \\
& Alcohol (4) & nd & nd & 79.5 & \\
& 10,10-DMA (1) & nd & 3.5 & nd & \\
& Other Impurities & nd & 0.2 & nd & No sample \\
\hline 4 & Melitracen (5 or 6) & 100 & 99.0 & nd & \\
& Alcohol (4) & nd & nd & 100 & \\
& 10,10-DMA (1) & nd & 0.8 & nd & \\
& Other Impurities & nd & 0.2 & nd & No sample \\
\hline 5 & Melitracen (5 or 6) & 99.9 & 99.1 & nd & nd \\
& Alcohol (4) & 0.1 & nd & 100 & \\
\hline
\end{tabular}




\begin{tabular}{|c|c|c|c|c|c|}
\hline & 10,10-DMA (1) & nd & 0.7 & nd & \\
& Other Impurities & nd & 0.2 & nd & \\
\hline \multirow{2}{*}{6} & Melitracen (5 or 6) & 100 & 99.3 & nd & 100 \\
& Alcohol (4) & nd & nd & 100 & nd \\
& 10,10-DMA (1) & nd & 0.5 & nd & nd \\
& Other Impurities & nd & 0.2 & nd & nd \\
\hline 7 & Melitracen (5 or 6) & 100 & 39.8 & 39.3 & 99.8 \\
& Alcohol (4) & nd & 60.2 & 60.7 & 0.2 \\
& 10,10-DMA (1) & nd & nd & nd & nd \\
& Other Impurities & nd & nd & nd & nd \\
\hline \multirow{2}{*}{8} & Melitracen (5 or 6) & 100 & 56.4 & 26.2 & 100 \\
& Alcohol (4) & nd & 43.6 & 73.8 & nd \\
& 10,10-DMA (1) & nd & nd & nd & nd \\
& Other Impurities & nd & nd & nd & nd \\
\hline
\end{tabular}

\section{Conclusions}

A full redesign of a current batch synthesis to a full flow setup has been possible, from the starting material to the final salt crystallization of the active pharmaceutical ingredient, Melitracen $\mathrm{HCl}$. The flow process was significantly simplified compared to the batch process,

341 with removal of a phase separation and usage of tetrahydrofuran (THF) only as a solvent

342 compared to the previous toluene-THF solvent mixture. All synthetic steps were carried out at

343 ambient temperature, whereas routine batch production requires active heating (up to $50^{\circ} \mathrm{C}$ ) and

344 cooling in several steps. The crystallization of the Melitracen $\mathrm{HCl}$ was proven possible in THF

345 with $2 \mathrm{M} \mathrm{HCl}$ in diethyl ether $\left(\mathrm{Et}_{2} \mathrm{O}\right)$ and eliminated a solvent swap to ethanol. The

346 crystallization was not optimized and would most likely be done with HCl gas, with an expected

347 additional gain in yield from the lower volume of solvent. The isolated yield in the given study

348 was approximately 85\%. The phase separation achieved with the decanter was higher than 99\%

349 product in the organic phase, with a HPLC purity of greater than 99\%. The isolated Melitracen

$350 \mathrm{HCl}$ was analyzed in accordance with the in-house release methods required for current batch 
351 production and all measurements were in accordance with requirements. A production of $60 \mathrm{~g} / \mathrm{h}$ 352 of isolated Melitracen $\mathrm{HCl}$ can be achieved with the flow setup. Furthermore, the setup

353 demonstrated great robustness towards fluctuations in reactant streams. The one-step hydrolysis

354 and dehydration could potentially be applicable for other Grignard additions, as could the 355 subsequent decanter phase separation.

356 Corresponding Author

357 *Telephone: +45 452528 27. Fax: +45 458822 58. E-mail: sk@kt.dtu.dk

\section{Acknowledgement}

359 The authors gratefully thank $\mathrm{H}$. Lundbeck A/S for financial contribution throughout the case 360 study of transforming the routine batch process to a flow method. 
363 (1) Suresh, P.; Basu, P. K. Journal of Pharmaceutical Innovation 2008, 3, 175-187.

364 (2) Browne, D. L.; Deadman, B. J.; Ashe, R.; Baxendale, I. R.; Ley, S. V. Organic Process Research \& Development 2011, 15, 693-697.

(3) Federsel, H.-J. Bioorganic \& Medicinal Chemistry 2010, 18, 5775-5794.

(4) Anderson, N. G. Organic Process Research \& Development 2012, 16, 852-869.

(5) Jiménez-González, C.; Poechlauer, P.; Broxterman, Q. B.; Yang, B.-S.; am Ende, D. J.; Baird, J.; Bertsch, C.; Hannah, R. E.; Dell’Orco, P.; Noorman, H.; Yee, S.; Reintjens, R.; Wells, A.; Massonneau, V.; Manley, J. Organic Process Research \& Development 2011, 15, 900-911.

372 (6) Plumb, K. Chemical Engineering Research and Design 2005, 83, 730-738.

373 (7) Jayadev, A.; Stiglitz, J. Health Affairs 2008, 28, 165-168.

374 (8) Aitken, M.; Berndt, E. R.; Cutler, D. M. Health Affairs 28, 151-160.

375

(9) Behr, A.; Brehme, V. A.; Ewers, C. L. J.; Grön, H.; Kimmel, T.; Küppers, S.; Symietz, I. Engineering in Life Sciences 2004, 4, 15-24.

377 (10) Sheldon, R. A. Green Chemistry 2007, 9, 1273-1283.

378

(11) Jiménez-González, C.; Ollech, C.; Pyrz, W.; Hughes, D.; Broxterman, Q. B.; Bhathela, N. Organic Process Research \& Development 2013, 17, 239-246.

(12) Jiménez-González, C.; Ponder, C. S.; Broxterman, Q. B.; Manley, J. B. Organic Process Research \& Development 2011, 15, 912-917.

(13) Poechlauer, P.; Manley, J.; Broxterman, R.; Gregertsen, B.; Ridemark, M. Organic Process Research \& Development 2012, 16, 1586-1590.

(14) Kockmann, N.; Roberge, D. M. Chemical Engineering \& Technology 2009, 32, 16821694.

386 (15) Roberge, D. M.; Bieler, N.; Thalmann, M. PharmaChem 2006, 5, 14-17.

387 (16) Popov, V. V. Pharmaceutical Chemistry Journal 1973, 7, 263-266.

388 (17) Webb, D.; Jamison, T. F. Chemical Science 2010, 1, 675-680. 
(18) Mascia, S.; Heider, P. L.; Zhang, H.; Lakerveld, R.; Benyahia, B.; Barton, P. I.; Braatz, R. D.; Cooney, C. L.; Evans, J. M. B.; Jamison, T. F.; Jensen, K. F.; Myerson, A. S.; Trout, B. L. Angewandte Chemie International Edition 2013, 52, 12359-12363.

(19) Heider, P. L.; Born, S. C.; Basak, S.; Benyahia, B.; Lakerveld, R.; Zhang, H.; Hogan, R.; Buchbinder, L.; Wolfe, A.; Mascia, S.; Evans, J. M. B.; Jamison, T. F.; Jensen, K. F. Organic Process Research \& Development 2014, 18, 402-409.

(20) Pedersen, M. J.; Holm, T. L.; Rahbek, J. P.; Skovby, T.; Mealy, M. J.; Dam-Johansen, K.; Kiil, S. Organic Process Research \& Development 2013, 17, 1142-1148.

(21) Anderson, N. G.; Burdick, D. C.; Reeve, M. M. Organic Process Research \& Development 2011, 15, 162-172.

(22) Chew, W.; Sharratt, P. Analytical Methods 2010, 2, 1412-1438.

(23) Wild, G. P.; Wiles, C.; Watts, P. Letters in Organic Chemistry 2006, 3, 419-425.

(24) Wiles, C.; Watts, P. Micro Reaction Technology in Organic Synthesis; 1st ed.; CRC Press: Boca Raton, Florida, 2011.

(25) Snead, D. R.; Jamison, T. F. Chemical Science 2013, 4, 2822-2827.

(26) Cervera-Padrell, A. E.; Nielsen, J. P.; Pedersen, M. J.; Christensen, K. M.; Mortensen, A. R.; Skovby, T.; Dam-Johansen, K.; Kiil, S.; Gernaey, K. V. Organic Process Research \& Development 2012, 16, 901-914.

(27) Christensen, K. M.; Pedersen, M. J.; Dam-Johansen, K.; Holm, T. L.; Skovby, T.; Kiil, S. Chemical Engineering Science 2012, 71, 111-117.

(28) Murray, P. R. D.; Browne, D. L.; Pastre, J. C.; Butters, C.; Guthrie, D.; Ley, S. V. Organic Process Research \& Development 2013, 17, 1192-1208.

(29) Hartman, R. L. Organic Process Research \& Development 2012, 16, 870-887.

(30) Hartman, R. L.; McMullen, J. P.; Jensen, K. F. Angewandte Chemie International Edition 2011, 50, 7502-7519.

(31) Roberge, D. M.; Ducry, L.; Bieler, N.; Cretton, P.; Zimmermann, B. Chemical Engineering \& Technology 2005, 28, 318-323.

(32) Baumann, M.; Baxendale, I. R. European Journal of Organic Chemistry 2017, 65186524.

(33) Baumann, M.; Baxendale, I. R.; Filipponi, P.; Hu, T. Organic Process Research \& Development 2017, 21, 2052-2059. 
420

421

422

423

424

425

426

427

428

429

430

431

432

433

434

435

436

437

438

439

440

441

442

443

444

(34) Filipponi, P.; Gioiello, A.; Baxendale, I. R. Organic Process Research \& Development 2016, 20, 371-375.

(35) Pastre, J. C.; Browne, D. L.; O’Brien, M.; Ley, S. V. Organic Process Research \& Development 2013, 17, 1183-1191.

(36) Carey, J. S.; Laffan, D.; Thomson, C.; Williams, M. T. Organic \& Biomolecular chemistry 2006, 4, 2337-2347.

(37) Roughley, S. D.; Jordan, A. M. Journal of Medicinal Chemistry 2011, 54, 3451-3479.

(38) Kopach, M. E.; Roberts, D. J.; Johnson, M. D.; McClary Groh, J.; Adler, J. J.; Schafer, J. P.; Kobierski, M. E.; Trankle, W. G. Green Chemistry 2012, 14, 1524-1536.

(39) Wong, S.-W.; Changi, S. M.; Shields, R.; Bell, W.; McGrarvey, B.; Johnson, M. D.; Sun, W.-M.; Braden, T. M.; Kopach, M. E.; Spencer, R. D.; Flanagan, G.; Murray, M. Organic Process Research \& Development 2016, 20, 540-550.

(40) Christensen, K. M.; Pedersen, M. J.; Dam-Johansen, K.; Holm, T. L.; Skovby, T.; Kiil, S. Chemical Engineering Science 2012, 71, 111-117.

(41) Mateos, C.; Rincón, J. A.; Villanueva, J. Tetrahedron Letters 2013, 54, 2226-2230.

(42) Barthe, P.; Guermeur, C.; Lobet, O.; Moreno, M.; Woehl, P.; Roberge, D. M.; Bieler, N.; Zimmermann, B. Chemical Engineering \& Technology 2008, 31, 1146-1154.

(43) Kockmann, N.; Roberge, D. M. Chemical Engineering \& Technology 2009, 32, 16821694.

(44) Roberge, D. M.; Bieler, N.; Mathier, M.; Eyholzer, M.; Zimmermann, B.; Barthe, P.; Guermeur, C.; Lobet, O.; Moreno, M.; Woehl, P. Chemical Engineering \& Technology 2008, 31, 1155-1161.

(45) Silverman, G. S.; Rakita, P. E. Handbook of Grignard Reagents; Silverman, G. S.; Rakita, P. E., Eds.; Marcel Dekker: New York, New York, 1996. 